\title{
ИЗМЕНЕНИЕ ПОКАЗАТЕЛЕЙ ЭНДОТЕЛИАЛЬНОЙ ФУНКЦИИ И ЖЕСТКОСТИ АРТЕРИАЛЬНОГО РУСЛА У БОЛЬНЫХ РЕВМАТОИДНЫМ АРТРИТОМ НА ФОНЕ ТЕРАПИИ ЛЕФЛУНОМИДОМ
}

\author{
(С Князева Л.А., Князева Л.И., Мещерина Н.С., Горяйнов И.И., Понкратов В.И.
}

\author{
Кафедра внутренних болезней №1 Курского государственного медицинского университета, Курск \\ E-mail: kafedra_n1@bk.ru
}

\begin{abstract}
В статье представлены результаты оценки влияния лефлуномида на показатели эндотелиальной функции и жесткости сосудистой стенки у больных ревматоидным артритом (РА) без сердечно-сосудистой патологии. Обследовано 46 больных PA, соответствующих классификационным критериям ACR (1987) или ACR/EULAR (2010). Bыполнены исследования эндотелиальной функции и артериальной ригидности, на основе выполнения контурного анализа пульсовой волны и проведения пробы с реактивной гиперемией на аппарате «АнгиоСкан-01», до лечения и после 12 месяцев терапии. Установлено, что у больных РА имеет место субклиническое поражение магистральных артерий, проявляющееся дисфункцией эндотелия на микро- и макроциркуляторном уровнях; повышением индексов аугментации (AIp), жесткости (SI) и отражения (RI), величина которых коррелировала с длительностью РА, индексом активности DAS28, уровнем РФ и концентрацией АЦЦП. Применение лефлуномида у больных РА сопровождалось статистически значимым снижением индекса DAS28. Показано, что наряду с высокой противовоспалительной активностью лефлуномид обладает свойством уменьшать признаки субклинического поражения артериального русла, что проявляется восстановлением функции эндотелия как в системе мелких резистивных сосудов (повышение индекса окклюзии по амплитуде), так и в крупных мышечных артериях (увеличение величины сдвига фаз между каналами), уменьшением жесткости магистральных артерий.
\end{abstract}

Ключевые слова: ревматоидный артрит, артериальная ригидность, лефлуномид, контурный анализ пульсовой волны, эндотелиальная дисфункция.

\section{CHANGES IN ENDOTHELIAL FUNCTION AND ARTERIAL STIFFNESS PARAMETERS IN PATIENTS WITH RHEUMATOID ARTHRITIS TREATED WITH LEFLUNOMIDE}

Knyazeva L.A., Knyazeva L.I., Meshcherina N.S., Goryainov I.I., Ponkratov V.I.

Department of Internal Diseases No. 1 of Kursk State Medical University, Kursk

The article presents the results of evaluation of leflunomide impact on endothelial function and vascular stiffness parameters in patients with rheumatoid arthritis (RA), but without cardiovascular diseases. 46 patients with RA satisfying ACR (1987) or ACR/EULAR (2010) classification criteria were examined. Investigations of endothelial function and arterial stiffness, based on the pulse wave contour analysis and the reactive hyperemia test ("AngioScan-01" device used), were conducted before the treatment and 12 months thereafter. It was determined that patients with RA suffered from subclinical damage of large arteries, characterized by endothelial dysfunction at micro- and macrocirculatory levels, and the increase in augmentation (AIp), stiffness (SI), and reflection (RI) indices, whose value correlated with RA duration, DAS28 activity index, RF level, and ACCP concentration. Leflunomide use in patients with RA was accompanied by statistically significant decrease in DAS28 index. It was shown that along with high anti-inflammatory activity leflunomide is also able of decreasing the signs of subclinical arterial damage, which is confirmed by the restoration of the endothelial function both in the system of small resistant vessels (increase in amplitude occlusion index) and large muscular arteries (increase in the value of phase shift between channels), and the decrease in stiffness of large arteries.

Keywords: rheumatoid arthritis, arterial stiffness, leflunomide, pulse wave contour analysis, endothelial dysfunction.

Ревматоидный артрит (РА) относится к группе иммуновоспалительных (аутоиммунных) заболеваний и характеризуется высокой распространенностью в популяции, быстрой инвалидизацией и неблагоприятным жизненным прогнозом. При этом высокий риск преждевременной летальности связан не столько c «тяжестью» самого заболевания, сколько с развитием обширной палитры коморбидной патологии, среди которой лидирующие позиции занимают кардиоваскулярные осложнения. Результаты проведенных исследований подтверждают, что системное воспаление при РА потенцирует проатерогенную перестройку стенок артерий, инициируя развитие оксидативного стресса, атерогенных дислипидемий, инсулинорезистентности, активации атерогенных Т-клеток [1]. Поэтому активность аутоиммунного воспаления в настоящее время рассматривается в качестве нового фактора риска атеросклеротического поражения сосудов, ранними признаками которого являются эндотелиальная дисфункция и артериальная жесткость. Кроме того, параметры жесткости сосудистой стенки, в первую очередь скорость распространения пульсовой волны (СРПВ) и 
индекс аугментации, включены в число тестируемых при диагностике субклинического поражения $\mathrm{CCC}$, а также в число факторов, влияющих на прогноз у пациентов с кардиоваскулярной патологий [18].

В настоящее время рекомендации Ассоциации Ревматологов России (АРP) основной целью фармакотерапии РА декларируют достижение ремиссии (или низкой активности) заболевания, снижение риска коморбидных заболеваний, ухудшающих качество жизни пациентов и прогноз заболевания [14]. По мнению директора Научноисследовательского института ревматологии РАМН академика Е.Л. Насонова, снижение кардиоваскулярного риска при РА является одним из приоритетных направлений научных исследований в российской ревматологии на ближайшие годы [9]. Реализация этих задач во многом зависит от оптимизации лечения PA c использованием стандартных базисных противовоспалительных препаратов (БПВП). Метотрексат по-прежнему является препаратом «Первой линии» для лечения РА, однако, как показывает клиническая практика, до 50\% пациентов либо демонстрируют недостаточную эффективность или плохую переносимость препарата, либо имеют противопоказания для его назначения [8]. В этих условиях эстафету в качестве БПВП в фармакотерапии РА БПВП принимает лефлуномид, доказавший в рандомизированных плацебоконтролируемых исследованиях высокую клиническую эффективность, не уступающую таковой метотрексату, также хорошую переносимость и безопасность [3, 11]. В то же время данные, касающиеся влияния лефлуномида на другой аспект стратегии лечения РА, а именно, снижение кардиоваскулярного риска, крайне немногочисленны и противоречивы. Результаты исследования QUEST-RA [20] свидетельствуют, что использование лефлуномида ассоциируется со снижением вероятности СС3 (ОР - 0,59; 95\% ДИ 0,43-0,79). Вместе с тем в ряде исследований было продемонстрировано повышение АД на фоне терапии лефлуномидом в основном у больных уже имеющих артериальную гипертензию (АГ) или другие кардиоваскулярные факторы риска [11]. При этом следует отметить, что действие лефлуномида на различные маркеры субклинического поражения сосудистого русла еще только предстоит изучить. Все вышесказанное определило цель настоящего исследования - оценить влияние лефлуномида на показатели эндотелиальной функции и жесткости сосудистой стенки у больных РА без сердечнососудистой патологии.

\section{МАТЕРИАЛЫ И МЕТОДЫ ИССЛЕДОВАНИЯ}

В исследовании приняли участие 46 пациентов с PA, соответствующих классификационным критериям ACR (1987) и/или ACR/EULAR (2010), с длительностью заболевания от 6 месяцев до 5 лет.

Критерии включения: информированное согласие пациента, активное течение РА в течение последних 3 месяцев; неэффективность предшествующей терапии метотрексатом или наличие противопоказаний к его назначению; сохраненная способность к самообслуживанию; отсутствие противопоказаний к применению лефлуномида.

Критерии исключения: низкая активность РА (индекс DAS28 менее 3,2 балла); наличие инфекционных процессов любой локализации, гепатита В или С, любой коморбидной патологии (АГ, ИБС, застойная сердечная недостаточность, СД), заболевания почек (уровень креатинина выше 133 мкмоль/л) и печени (уровни АСТ, АЛТ, билирубина в 3 и более раза превышающие нормальные значения), ожирение (ИМТ более

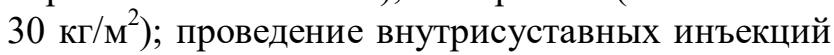
глюкокортикоидов менее чем за 4 недели до рандомизации; прием преднизолона или его эквивалентов внутрь в дозе более 20 мг/сут.

Среди обследованных больных было 34 женщины и 12 мужчин, средний возраст которых составил 39,4 [28,5; 46,1] года, средняя длительность болезни - 21,8 [8,3; 45,6] мес. Активность заболевания по DAS28 была умеренной у 6 пациентов и высокой у 40 больных. У 74\% $(\mathrm{n}=34)$ больных имела место II и у $26 \%(\mathrm{n}=12)$ - III рентгенологическая стадия по Штейнброккеру. До включения в исследование пациенты получали предшествующую терапию БПВП: МТ - 63\% (n = 29), сульфасалазин - 11\% (n = 5), лефлуномид - 26\% $(\mathrm{n}=12)$, а так же нестероидные противовоспалительные препараты (НПВП) - 41\% и глюкокортикоиды - 22\%. Внесуставные проявления заболевания были определены у 29 (63\%) больных, среди которых наиболее часто встречались ревматоидные узелки $(\mathrm{n}=9)$ и амиотрофический синдром (n = 18), также наблюдались анемия $(\mathrm{n}=4)$, нейропатия $(\mathrm{n}=2)$ и капиллярит $(\mathrm{n}=1)$.

Среди пациентов, включенных в исследование, у 7 (15\%) больных имел место отягощенный по СC3 семейный анамнез, при оценке по шкале SCORE определен умеренный $(\mathrm{n}=28)$ или низкий $(\mathrm{n}=18)$ кардиоваскулярный риск. 
В зависимости от уровня РФ и/или АЦЦП в сыворотке крови обследованные больные были разделены на 2 группы: в 1-ю $(\mathrm{n}=26)$ вошли пациенты с РФ/АЦЦП-серонегативным РА, во 2-ю $(\mathrm{n}=20)$ - больные с РФ/АЦЦП-серопозитивным вариантом заболевания.

Группу контроля составили 26 здоровых лиц в возрасте 38,8 [31,6; 46,7] года (из них 19 (73\%) женщин и 7 (27\%) мужчин).

В ходе исследования всем больным с РА проводилось обследование в соответствии с рекомендациями АРP [15], определение кардиоваскулярного риска по шкале SCORE. Уровень IgM РФ и АЦЦП оценивали иммуноферментным методом («ORGen TecDiagnostika», Германия).

Исследование эндотелиальной функции и артериальной ригидности включало оценку контурного анализа пульсовой волны и проведение пробы с реактивной гиперемией на аппарате «АнгиоСкан-01» (OOO «АнгиоСканЭлектроникс», Россия) в соответствии с требованиями по подготовке испытуемого и процедуре проведения тестов [14].

Протокол исследования: контурный анализ пульсовой волны и окклюзионная проба проводились в затемненной комнате после 15. минутного отдыха, в утренние часы, натощак, в удобном сидячем положении с неподвижными кистями с фотоплетизмографическими датчиками на концевых фалангах указательных пальцев. При оценке функции эндотелия окклюзионная манжета до надувания свободно пропускала палец в зазор между манжетой и кожей плеча, располагалась на предплечье, на 2-3 см ниже локтевого сгиба. За 24 часа до исследования исключался прием кофеина, алкоголя и других стимуляторов, физические нагрузки и курение.

По результатам контурного анализа пульсовой волны анализировались такие параметры, как индекс жесткости (SI, stiffnessindex), индекс отражения (RI, reflectionindex), индекс аугментации (Alp, augmentationindex), центральное систолическое давление - прогноз (Spa, SystolicPressureAortic prognosis). В ходе выполнения окклюзионной пробы оценивали индекс окклюзии по амплитуде и сдвиг фаз между каналами.

В обеих группах в соответствии с инструкцией по применению назначали лефлуномид по 100 мг/сут. в первые 3 дня, затем постоянно по 20 мг/сут. Анализ результативности вмешательства базировался на промежуточных «суррогатных» критериях. Для оценки клинической эффективности терапии использовали критерии EULAR, основанные на динамике индекса DAS28.
Оценку функционального состояния эндотелия и параметров артериальной ригидности у больных РА проводили дважды: до лечения и после 12 месяцев терапии лефлуномидом.

Статистическая обработка цифровых данных произведена с применением стандартного пакета прикладных программ Microsoft Excel и STATISTICA Base for Windows версия 6.0 (StatSoft). Проверку параметров на нормальность распределения проводили по КолмогоровуСмирнову. Полученные результаты представлены в виде медианы (Me) с интерквартильным размахом 25-75 процентиль ([25Q;75Q]). Данные для показателей с номинальным (качественным) типом шкалы представлены в виде абсолютных частот и доли в группе в процентах. Для установления значимости различий по количественным признакам применялся непараметрический дисперсионный анализ (ANOVA): до лечения для независимых групп по критерию Крускала-Уоллиса, на фоне лечения для зависимых групп по критерию Вилкоксона. Для оценки зависимости между изучаемыми количественными параметрами рассчитывался коэффициент ранговой корреляции Спирмена (r). Во всех процедурах статистического анализа за критический уровень значимости нулевой статистической гипотезы принимали $\mathrm{p}=0,05$.

\section{РЕЗУЛЬТАТЫ ИССЛЕДОВАНИЯ И ИХ ОБСУЖДЕНИЕ}

В нашем исследовании для оценки эндотелиальной функции у больных РА без сопутствующей кардиоваскулярной патологии использовался аппарат «АнгиоСкан-01» (Россия), в основу действия которого положен метод фотоплетизмографии, позволяющий регистрировать пульсовую волну с пальцев обеих рук. Фотоплетизмографический сигнал формируется благодаря изменению пульсового объема кровотока, преимущественно за счет динамики изменения диаметра пальцевых артерий, при этом вклад резистивных сосудов (артериол) не превышает $10-20 \%$. В основе теста оценки функции эндотелия лежит феномен локального снижения тонуса артерий при развитии реактивной гиперемии. После снятия окклюзии происходят изменения кровотока на участке дистальнее места пережатия. Наиболее характерными проявлениями являются изменение кровенаполнения капилляров пальца и увеличение времени распространения пульсовой волны, что позволяет оценить состояние эндотелиальной функции мелких резистивных артерий и артериол. 
В результате проведения пробы с реактивной гиперемией в обеих группах больных $\mathrm{PA}$ установлена приблизительно одинаковая частота снижения постокклюзионной амплитуды сигнала (ПАС). В 1-й группе снижение ПАС выявлено у $80 \%(\mathrm{n}=21)$ больных РА, во 2-й группе - у 85\% $(\mathrm{n}=17)$ (рис. 1). При этом обращает на себя внимание значимое увеличение доли пациентов с ПАС менее 1,5 в группе РФ/АЦЦП-серопозитивного РА до $45 \%$ vs $26 \%$ у больных с серонегативным по РФ/АЦЦП вариантом.

Оценка индекса окклюзии показала его снижение у больных РА по сравнению с контролем в 1-й группе в среднем на $28,1 \%$ $(\mathrm{p}=0,03)$ и на $62,1 \%(\mathrm{p}=0,001)-$ во 2-й группе (рис. 2). При этом статистически значимой разницы между данным показателем в сравниваемых группах больных РА получено не было. Так же по данным окклюзионной пробы в обследованных группах установлено уменьшение величины сдвига фаз между каналами в сравнении с контролем в среднем в 1,6 раза $(\mathrm{p}=0,006)$ в 1 -й группе и в 2,1 раза $(\mathrm{p}=0,001)-\mathrm{y}$ больных 2-й группы.

При этом следует отметить, что уменьшение величины сдвига фаз между каналами у обследованных нами больных РА указывает на нарушение функции эндотелия в крупных мышечных артериях. В основе механизма возникновения данного феномена лежит влияние монооксида азота (NO) на гладкомышечные клетки артериальной стенки крупных артерий (плечевая и лучевая) мышечного типа, обусловливающее снижение СРПВ на исследуемом участке артериального русла [13]. Таким образом, полученные нами данные свидетельствуют о наличии у больных PA вазомоторной дисфункции эндотелия не только в системе мелких резистивных сосудов (снижение индекса окклюзии по амплитуде), но и в крупных мышечных артериях (уменьшение величины сдвига фаз между каналами).

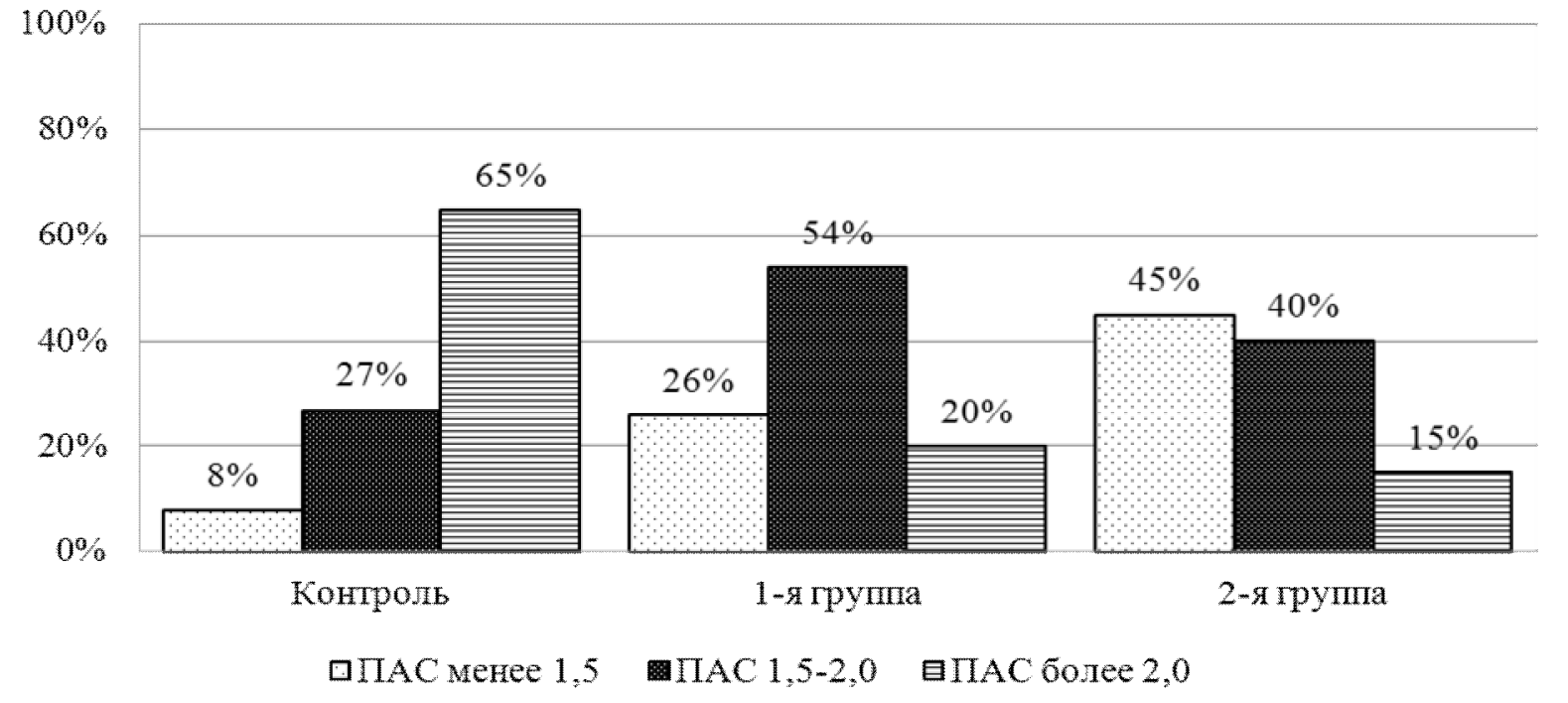

Рис. 1. Постокклюзионный прирост амплитуды сигнала у больных РА.
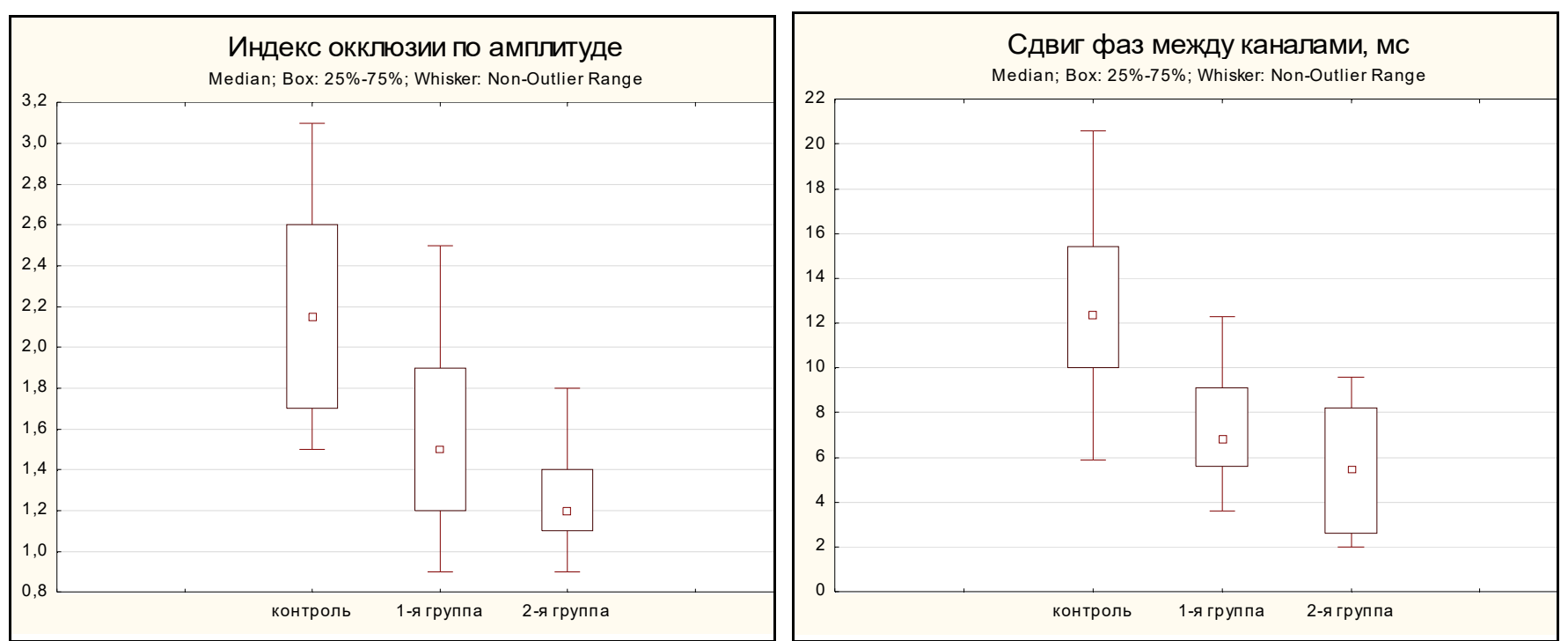

Рис. 2. Показатели окклюзионной пробы у больных РА. 


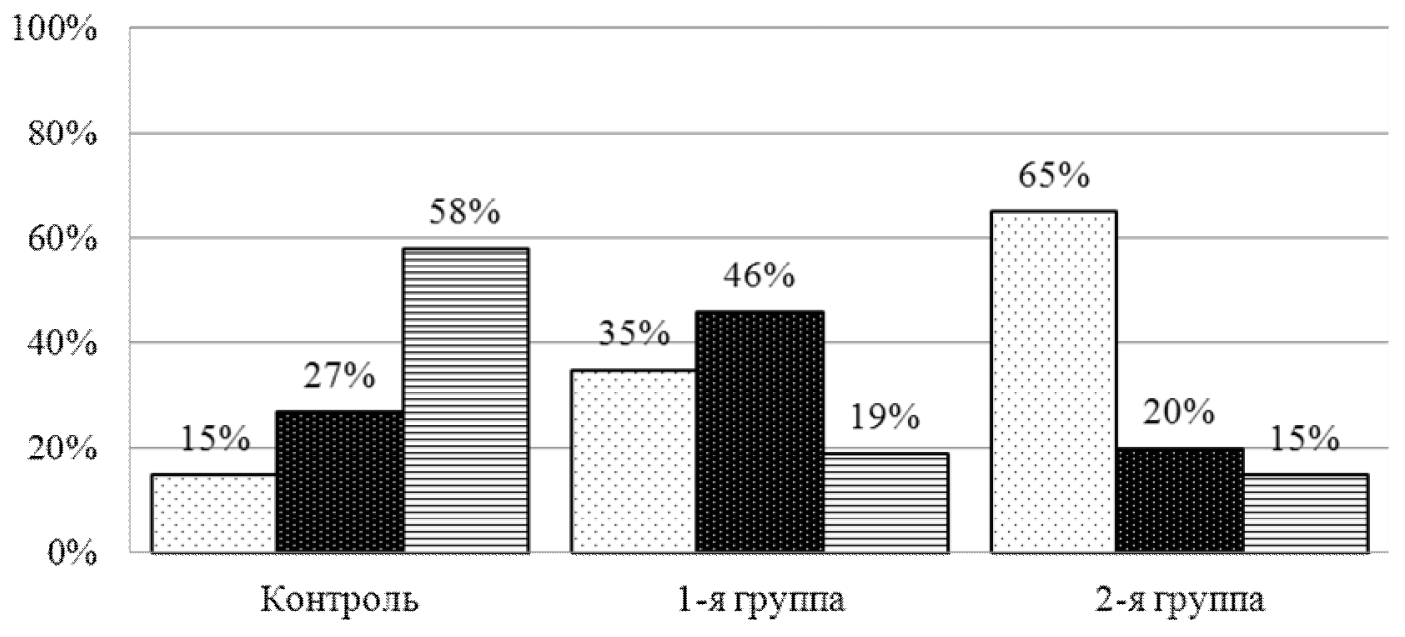

口Тип А в Тип В вТип С

Рис. 3. Распределение больных в зависимости от типа пульсовых кривых при различной длительности РА и клинико-иммунологических вариантах заболевания.

В нашей работе проведено изучение параметров эластичности и жесткости крупных проводящих артерий и показателей сосудистого тонуса мелких мышечных артерий и артериол у больных РА на основе контурного анализа пульсовой волны объема, зарегистрированной с помощью инфракрасного датчика, форма которой взаимосвязана со СРПВ по артериальному дереву, a регистрируемый сигнал не зависит от локальных сосудистых изменений лоцируемой области, и полностью определяется состоянием крупных артерий проводящего типа и сосудистым тонусом [14].

Проведенный контурный анализ пульсовой волны показал, что у 58\% лиц контрольной группы регистрировались кривые типа «С», при этом у большинства обследованных больных РА определены кривые типа «А» и «В» (рис. 3), которые рассматриваются как патологические, характеризующиеся уменьшением временного промежутка между прямой и отраженной пульсовыми волнами. При этом только у 5 больных РА из 1-й группы и у 3 больных 2-й группы определен тип «С» кривых пульсовой волны. Следует отметить, что кривые типа «А» были зарегистрированы у $65 \%$ больных с РФ/АЦЦП-серопозитивным РА, в группе РФ/АЦЦП-серонегативного РА только у $46 \%$ пациентов выявлены волны типа «В».

В ходе проведенного исследования установлено статистически значимое повышение индекса AІр во всех группах обследованных больных РА в сравнении с контролем (-12,1 [6,8; $-18,6] \%$, при этом у больных 2-й группы среднегрупповые значения AIp $\quad(16,4 \quad[10,8$; $38,1]$ \%) были выше, чем в 1-й группе в среднем в 1,5 раза $(\mathrm{p}=0,036)$. Выявлено увеличение индекса жесткости (SI) у пациентов с РФ/АЦЦП-серопозитивным РА в среднем на $11,2 \%(p=0,022)$ по сравнению с его значением в группе больных с серонегативным по РФ/АЦЦП заболеванием $(8,1[7,4 ; 9,1] \%)$. Индекс отражения (RI) у больных 1-й группы в среднем в 1,3 раза $(\mathrm{p}=0,048)$ превышал величину контроля $(25,6$ $[20,8 ; 36,9] \%)$, однако в 1,8 раза $(p=0,001)$ был ниже данного показателя у больных 2-й группы $(62,0[43,9 ; 74,3] \%)$.

Проведенный корреляционный анализ установил наличие достоверных взаимосвязей между длительностью РА, индексом окклюзии по амплитуде $(\mathrm{r}=-0,61, \mathrm{p}=0,001)$ и показателем сдвига фаз по каналам $(\mathrm{r}=-0,48, \mathrm{p}=0,02)$; обратные зависимости выявлены между индексом окклюзии по амплитуде и DAS28 ( $\mathrm{r}=-0,58$, $\mathrm{p}=0,05)$, показателем сдвига фаз по каналам и уровнем РФ $(\mathrm{r}=-0,64, \mathrm{p}=0,01)$. Кроме того, корреляционные связи определены между длительностью РА и индексами AIp и SI ( $\mathrm{r}=0,53$, $\mathrm{p}=0,01$ и $\mathrm{r}=0,49, \mathrm{p}=0,04$ соответственно); индексами DAS28 и AIp, SI ( $\mathrm{r}=0,46, \mathrm{p}=0,018$ и $\mathrm{r}=0,51, \mathrm{p}=0,02$ соответственно); уровнем РФ и индексами AIp, SI и RI ( $r=0,56, p=0,01 ; r=0,68$, $\mathrm{p}=0,04$ и $\mathrm{r}=0,42, \mathrm{p}=0,035$ соответственно), концентрацией АЦЦП и индексами AIp, SI и RI $(r=0,48, p=0,03 ; r=0,62, p=0,018 ; r=0,48$, $\mathrm{p}=0,044$ соответственно). Результаты корреляционного анализа отражают существенное значение длительности и активности заболевания в развитии эндотелиальной дисфункции, повышении ригидности сосудистой стенки при РА, что было показано нами и в более ранних работах [5].

Согласно рекомендациям ACR, лефлуномид наряду с метотрексатом относится к препаратам 1-го выбора при стартовой терапии РА, а экспертами EULAR лефлуномид признан альтернативой метотрексату [6]. В связи с чем, безусловный интерес представляло изучение влияния лефлуномида на функциональное состояние эндотелия и 
артериальную ригидность, являющихся маркерами субклинического поражения артериального русла и факторами риска кардиоваскулярных осложнений.

Анализ противовоспалительной активности лефлуномида показал, что у больных РА на фоне длительного приема препарата было достигнуто статистически значимое снижение СОЭ и СРБ, более выраженные изменения данных показателей имели место при РФ/АЦЦП-серонегативном варианте заболевания (таб. 1). Кроме того, через 12 месяцев лечения лефлуномидом во 2-й группе больных PA установлено снижение уровня IgM РФ в 2,4 раза $(\mathrm{p}<0,001)$ и АЦЦП в 3,1 раза ( $\mathrm{p}<0,001)$, надо отметить, что у 3 (15\%) РФ/АЦЦП-серопозитивных больных произошла сероконверсия и при повторном исследовании $\operatorname{IgM~РФ~в~сыворотке~не~определялся.~}$

На фоне применения лефлуномида, начиная с 4-й недели лечения, было достигнуто значимое уменьшение DAS28, к концу наблюдения клиническое улучшение (хороший/умеренный эффект по критериям EULAR) был определен у 61\% больных $(\mathrm{n}=28)$, ремиссия достигнута у $33 \%$ пациентов с PA $(\mathrm{n}=15)$. Более подробный анализ результатов 12-месячной терапия лефлуномидом показал наличие хорошего эффекта у 13\% больных $(\mathrm{n}=6)$, умеренный эффект наблюдался у 46\% пациентов (n=21), отсутствие клинической динамики выявлено у 6\% $(\mathrm{n}=3)$. Следует отметить, что при исходно одинаковой активности РА в сравниваемых группах больных, большая эффективность противовоспалительного действия лефлуномида была определена при серонегативном по РФ/АЦЦП варианте болезни (рис. 4).

Переносимость лефлуномида в целом была хорошей, у 8 (17\%) пациентов было зарегистрировано развитие нежелательных явлений, не потребовавших отмены препарата. Наиболее частыми и определенно связанными с проводимой терапией являлись нарушения функции ЖКТ (диарея $(\mathrm{n}=1)$, метеоризм и тошнота $(\mathrm{n}=3))$, повышенное выпадение волос $(\mathrm{n}=2)$, аллергические кожные проявления в виде дерматита $(\mathrm{n}=2)$. Следует отметить, что дестабилизации уровня АД у обследованных больных на фоне длительного лечения лефлуномидом зарегистрировано не было.

Изучение влияния лефлуномида на показатели вазомоторной функции эндотелия при проведении пробы с реактивной гиперемией показало значимое увеличение количества пациентов с ПАС более 2,0 с $18 \%(\mathrm{n}=7)$ до $44 \%(\mathrm{n}=17)$ при РФ/АЦЦП-серонегативном РА и с $10 \%(\mathrm{n}=4)$ до $25 \%(\mathrm{n}=10)$ больных - при серопозитивном по РФ/АЦЦП варианте заболевания. Также выявлено уменьшение числа пациентов с ПАС менее 1,5 с $31 \%(\mathrm{n}=12)$ до $10 \%(\mathrm{n}=4)$ в 1-й группе и с $44 \%(n=17)$ до $25 \%(n=9)$ больных во 2-й группе.

Таблица 1

Влияние лефлуномида на лабораторные показатели активности РА

\begin{tabular}{|c|c|c|c|c|c|c|}
\hline \multirow{2}{*}{ Показатель } & \multicolumn{4}{|c|}{ Группы обследованных больных РА } \\
\cline { 2 - 7 } & \multicolumn{3}{|c|}{1 группа $(\mathrm{n}=26)$} & $\mathrm{c}$ & 2-я группа $(\mathrm{n}=20)$ \\
\cline { 2 - 7 } & исходно & через 12 месяцев & $\mathrm{p}$ & исходно & через 12 месяцев & $\mathrm{p}$ \\
\hline СОЭ, мм/ч & $32,9[22,6 ; 49,8]$ & $21,6[11,3 ; 32,2]$ & $\mathrm{p}=0,0001$ & $36,4[20,7 ; 52,1]$ & $26,7[14,6 ; 34,6]$ & $\mathrm{p}=0,004$ \\
\hline СРБ, мг \% & $2,1[0,98 ; 6,3]$ & $1,2[0,6 ; 1,4]$ & $\mathrm{p}=0,002$ & $2,8[1,1 ; 7,8]$ & $1,53[1,2 ; 2,1]$ & $\mathrm{p}=0,006$ \\
\hline
\end{tabular}

Примечание: полученные результаты представлены в виде медианы (Ме) с интерквартильным размахом 25-75 процентиль ([25Q; 75Q]); p - по сравнению с исходными значениями в данной группе.

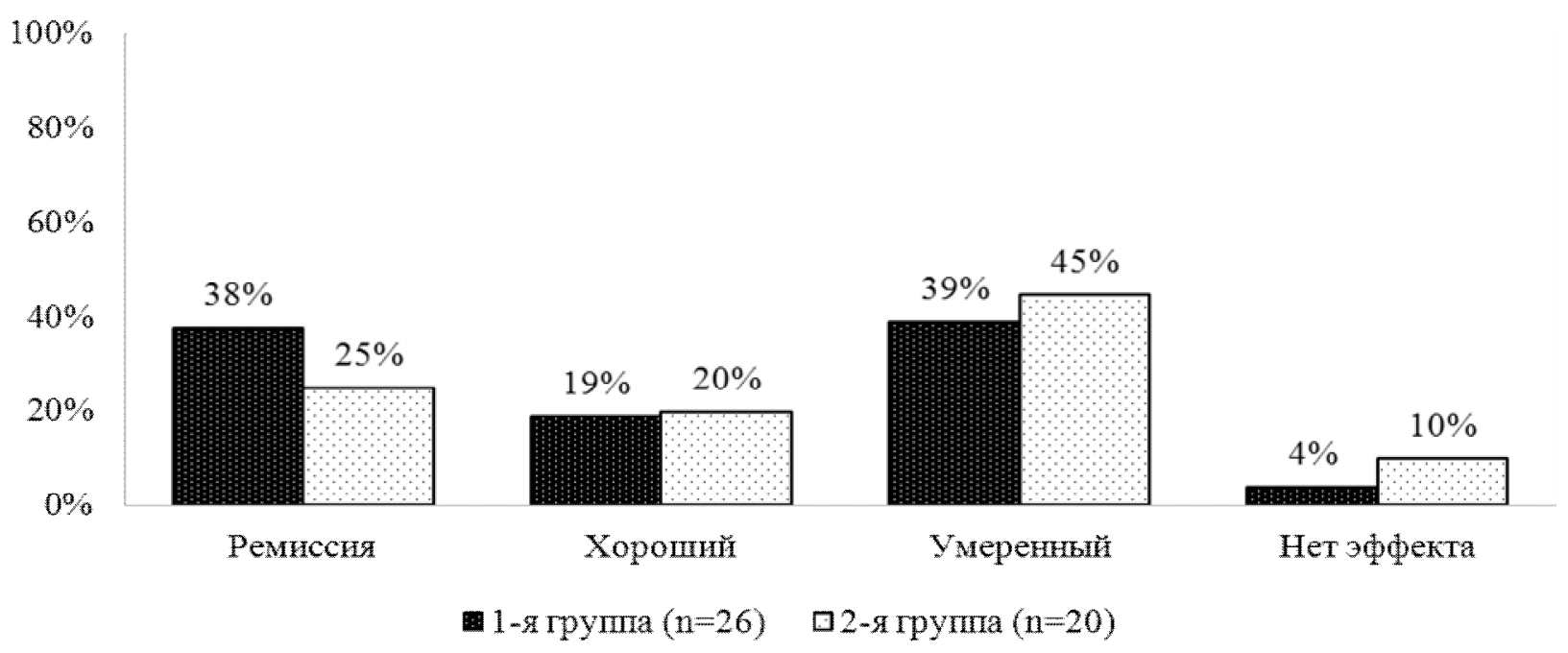

Рис. 4. Оценка эффективности терапии лефлуномидом по критериям EULAR у больных PA. 
Таблица 2

Параметры окклюзионной пробы у больных РА после терапии лефлуномидом

\begin{tabular}{|c|c|c|c|c|c|c|c|}
\hline \multirow{3}{*}{ Показатель } & \multicolumn{7}{|c|}{ Группы обследованных } \\
\hline & \multirow{2}{*}{$\begin{array}{c}\text { Контроль } \\
(\mathrm{n}=26)\end{array}$} & \multicolumn{3}{|c|}{ 1-я группа (n = 26) } & \multicolumn{3}{|c|}{ 2-я группа $(\mathrm{n}=20)$} \\
\hline & & исходно & $\begin{array}{l}\text { через } 12 \\
\text { месяцев }\end{array}$ & $\mathrm{p}$ & исходно & $\begin{array}{l}\text { через } 12 \\
\text { месяцев }\end{array}$ & $\mathrm{p}$ \\
\hline $\begin{array}{c}\text { Индекс окклюзии } \\
\text { по амплитуде }\end{array}$ & $\begin{array}{c}2,1 \\
{[1,8 ; 2,3]}\end{array}$ & $\begin{array}{c}1,5 \\
{[1,2 ; 1,9]}\end{array}$ & $\begin{array}{c}1,8 \\
{[1,5 ; 2,2]}\end{array}$ & $\mathrm{p}=0,01$ & $\begin{array}{c}1,2 \\
{[0,9 ; 1,5]}\end{array}$ & $\begin{array}{c}1,5 \\
{[1,1 ; 1,8]}\end{array}$ & $\mathrm{P}=0,04$ \\
\hline $\begin{array}{c}\text { Сдвиг фаз между } \\
\text { каналами, м/с }\end{array}$ & $\begin{array}{c}12,5 \\
{[10 ; 15,4]}\end{array}$ & $\begin{array}{c}6,8 \\
{[5,6 ; 9,1]}\end{array}$ & $\begin{array}{c}10,8 \\
{[8,2 ; 15,2]}\end{array}$ & $p=0,004$ & $\begin{array}{c}5,45 \\
{[2,6 ; 8,2]}\end{array}$ & $\begin{array}{c}7,8 \\
{[5,9 ; 9,8]}\end{array}$ & $\mathrm{P}=0,018$ \\
\hline
\end{tabular}

Примечание: полученные результаты представлены в виде медианы $(\mathrm{Me})$ с интерквартильным размахом 25-75 процентиль ([25Q; 75Q]); p - по сравнению с исходными значениями в данной группе.

Изменения показателей контурного анализа пульсовой волны у больных РА

Таблица 3 на фоне терапии лефлуномидом

\begin{tabular}{|c|c|c|c|c|c|c|c|}
\hline \multirow{3}{*}{ Показатель } & \multicolumn{7}{|c|}{ Группы обследованных } \\
\hline & \multirow{2}{*}{$\begin{array}{c}\text { Контроль } \\
(\mathrm{n}=26)\end{array}$} & \multicolumn{3}{|c|}{ 1-я группа (n = 26) } & \multicolumn{3}{|c|}{ 2-я группа $(\mathrm{n}=20)$} \\
\hline & & исходно & $\begin{array}{l}\text { через } 12 \\
\text { месяцев }\end{array}$ & $\mathrm{p}$ & исходно & $\begin{array}{l}\text { через } 12 \\
\text { месяцев }\end{array}$ & $\mathrm{p}$ \\
\hline Alp, \% & $\begin{array}{c}-12,1 \\
{[6,8 ;-18,6]}\end{array}$ & $\begin{array}{c}11,6 \\
{[18,3 ;-4,1]}\end{array}$ & $\begin{array}{c}-8,6 \\
{[9,7 ;-16,2]}\end{array}$ & $p=0,0001$ & $\begin{array}{c}16,4 \\
{[10,8 ; 38,1]}\end{array}$ & $\begin{array}{c}10,8 \\
{[4,6 ; 24,1]}\end{array}$ & $p=0,04$ \\
\hline $\mathrm{SI}, \mathrm{m} / \mathrm{c}$ & $\begin{array}{c}6,7 \\
{[5,9 ; 7,8]}\end{array}$ & $\begin{array}{c}8,1 \\
{[7,4 ; 9,1]}\end{array}$ & $\begin{array}{c}7,4 \\
{[6,2 ; 7,6]}\end{array}$ & $p=0,001$ & $\begin{array}{c}9,1 \\
{[7,8 ; 10,6]}\end{array}$ & $\begin{array}{c}8,1 \\
{[7,9 ; 9,0]}\end{array}$ & $p=0,026$ \\
\hline RI, \% & $\begin{array}{c}25,6 \\
{[20,8 ; 36,9]}\end{array}$ & $\begin{array}{c}45,7 \\
{[39,5 ; 54,3]}\end{array}$ & $\begin{array}{c}30,5 \\
{[27,1 ; 34,5]}\end{array}$ & $p=0,008$ & $\begin{array}{c}62,0 \\
{[43,9 ; 74,3]}\end{array}$ & $\begin{array}{c}40,2 \\
{[28,3 ; 60,2]}\end{array}$ & $p=0,036$ \\
\hline Spa, мм рт. ст. & $\begin{array}{c}118 \\
{[105 ; 123]}\end{array}$ & $\begin{array}{c}125 \\
{[121 ; 130]}\end{array}$ & $\begin{array}{c}122 \\
{[118 ; 128]}\end{array}$ & $N S$ & $\begin{array}{c}126 \\
{[118 ; 130]}\end{array}$ & $\begin{array}{c}125 \\
{[118 ; 128]}\end{array}$ & $N S$ \\
\hline
\end{tabular}

Примечание: полученные результаты представлены в виде медианы (Ме) с интерквартильным размахом 25-75 процентиль ([25Q; 75Q]); p - по сравнению с исходными значениями в данной группе, NS - различия статистически не значимы.

Индекс окклюзии по амплитуде на фоне терапии лефлуномидом у больных 1-й группы увеличился по сравнению с исходными значениями в среднем на $26 \%(\mathrm{p}=0,01)$ и статистически значимо не отличался от контроля (табл. 2). Во 2-й группе пациентов данный показатель увеличился на $18 \%(\mathrm{p}=0,04)$, однако оставался ниже контроля в среднем на $14 \%$ $(\mathrm{p}<0,05)$ и на $28 \%(\mathrm{p}<0,05)$ был меньше, чем в группе больных с серонегативным по РФ/АЦЦП вариантом РА.

Установлено нарастание величины сдвига фаз между каналами в сравнении с исходными значениями в 1-й группе в среднем в 1,6 раза $(\mathrm{p}=0,004)$ и в 1,3 раза $(\mathrm{p}=0,018)$ - во 2-й группе. При РФ/АЦЦП-серонегативном РА данный показатель достигал значений контрольной группы, что указывает на восстановление функции эндотелия в крупных мышечных артериях на фоне длительной терапии лефлуномидом.

Анализ изменений типа пульсовых волн после терапии лефлуномидом показал, что в группе больных с РФ/АЦЦП-серонегативным РА увеличилось количество пациентов, у которых регистрировались кривые типа «С», характерные для лиц молодого возраста с неизмененной сосудистой стенкой, надо отметить, что тип волны «А» сохранялся только у четырех больных этой группы. При серопозитивном по РФ/АЦЦП варианте РА увеличилось количество больных с кривыми волн типа «С» и «В» соответственно на $15 \%$ на $21 \%$, что свидетельствует об улучшении структурно-функциональных свойств магистральных артерий эластического типа, постольку тип кривой «В» является прогностически более благоприятным, чем тип «А», а волны типа «С» характерны для здоровых людей молодого возраста [14].

Изучение характеристик контурного анализа пульсовой волны после терапии лефлуномидом у больных 1-й группы установило снижение индекса аугментации (AIp) до отрицательного значения; во 2-й группе данный показатель уменьшился в 1,8 раза $(\mathrm{p}=0,04)$ (табл. 3$)$. Важно отметить, что индекс аугментации является 
основным показателем, количественно характеризующим тип кривой пульсовой волны. Индекс AIp рассчитывается как разница между вторым и первым систолическими пиками давления пульсовой волны, выраженная в процентах от пульсового давления, при этом в норме отраженная компонента всегда меньше прямой, поэтому индекс AIp - отрицательный [13]. Выявленные изменения индекса AIp на фоне приема лефлуномида указывают на уменьшение жесткости артериальной стенки у обследованных больных РА.

У больных РА после терапии лефлуномидом так же определено уменьшение индекса жесткости (SI), при этом в 1-й группе данный показатель достиг значения контроля, во 2-й группе - уменьшение в среднем на $11 \%$ $(\mathrm{p}=0,026)$.

Известно, что индекс жесткости отражает среднюю СРПВ по крупным резистивным сосудам, оценка данного показателя основана на определении временного интервала между ранней (прямая) и поздней (отраженная) систолическими волнами. С увеличением ригидности крупных резистивных сосудов, в первую очередь аорты, происходит повышение индекса жесткости вследствие возрастания СРПВ, определение которой в настоящее время рассматривается как независимый фактор риска неблагоприятных сердечно-сосудистых событий [19]. При этом необходимо подчеркнуть, что у обследованных больных PA изменения индекса SI не зависели от уровня АД в проксимальном отделе аорты и брахиоцефальных сосудах, потому как величина Spa y больных PA ни исходно, ни после проведенной терапии не имела достоверных межгрупповых отличий.

Кроме того, на фоне лечения лефлуномидом выявлено уменьшение индекса отражения, который характеризует тонус мелких мышечных артерий и наличие их спазма, являющегося важным компонентом патогенеза СС3. Если в 1-й группе больных контурный анализ пульсовой волны показал снижение индекса отражения до значений контроля, то у больных 2-й группы индекс отражения уменьшился в среднем в 1,6 раза $(\mathrm{p}=0,036)$ при сохранении статистически значимых отличий с величиной контрольной группы. Выявленные изменения показателей контурного анализа пульсовой волны у больных PA после 12-месячной терапии лефлуномидом указывают на улучшение эластических свойств артериального русла, что сопряжено со снижением кардиоваскулярного риска.

Таким образом, полученные результаты свидетельствуют о наличии вазопротективного действия лефлуномида на стенки крупных сосудов эластического типа и мелких артерий мышечного типа, что подтверждается изменениями параметров контурного анализа пульсовой волны (снижение индексов AIp, SI и RI) в обеих группах обследованных больных PA после 12 месяцев терапии. При этом большая активность корригирующего действия лефлуномида на параметры эндотелиальной функции и ригидности артериальной стенки в различных отделах сосудистого русла определена при РФ/АЦЦП-серонегативном варианте РА.

В качестве механизмов, определяющих вазопротективные свойства лефлуномида, можно рассматривать угнетение синтеза пирамидина рибонуклеотида и подавление активности митохондриального фермента дигидрооротатдегидрогеназы. Последний обеспечивает выработку пиримидиновых нуклеотидов, недостаток которых приводит к нарушению синтеза ДНК и РНК лимфоцитов, блокировке клеточного цикла в $\mathrm{G} 1 / \mathrm{S}$ фазе, что сопровождается развитием цитостатического эффекта лефлуномида в отношении активированных клеток (Т- и В-лимфоцитов, моноцитов, макрофагов) [2]. Кроме того, доказано, что лефлуномид блокирует экспрессию молекул клеточной адгезии, подавляет миграцию нейтрофилов в места воспаления, представление антигенов, секрецию цитокинов, прежде всего ФНО $\alpha$, ИЛ-1 $\beta$, ИЛ-6, и матриксных протеиназ [16], которые одновременно являются основными медиаторами прогрессирования РА и иммуновоспалительных механизмов развития атеросклероза [4, 17]. Кроме того, эндотелио-протективное действие лефлуномида может быть обусловлено снижением продукции свободных радикалов в моноцитах [16], в результате чего не происходит угнетения синтеза NO, снижение уровня которого лежит в основе падения вазодилатационного потенциала, адгезии моноцитов и тромбоцитов к эндотелию сосудов, пролиферации гладкомышечных клеток, образованию неоинтимы, что, в конечном счете, индуцирует процессы атерогенеза [7].

Таким образом, анализ полученных данных подтвердил высокую клиническую эффективность терапии лефлуномидом, что согласуется с результатами исследований других авторов [3, 6, 16]. Кроме того, установлено, что лефлуномид, наряду с противовоспалительной активностью, обладает свойством уменьшать признаки субклинического поражения артериального русла, что проявляется восстановлением функции эндотелия как в системе мелких резистивных сосудов (повышение индекса окклюзии по амплитуде), так и в крупных мышечных артериях (увеличение величины сдвига фаз между каналами), 
уменьшением жесткости магистральных артерий. Достигнутые изменения структурнофункционального состояния сосудистой стенки под влиянием терапии лефлуномидом потенциально связаны со снижением кардиоваскулярного риска на фоне подавления хронического воспаления при РА, что открывает перспективы дальнейших исследований по эффективности применения БПВП с позиций профилактики ССЗ у данной категории больных.

\section{ЛИТЕРАТУРА}

1. Арабидзе Г.Г. Клиническая иммунология атеросклероза - от теории к практике // Атеросклероз и дислипидемии. - 2013. - № 1. - С. 4-19.

2. Балабанова Р.М. Эффективность и безопасность препарата лефлуномид (Арава) при ревматических заболеваниях // Русский медицинский журнал. 2010. - Том 18, № 1. - С. 744-746.

3. Балабанова Р.М., Дубинина Т.В., Горячев Д.В., Шахраманова Е.Л., Аношенкова О.Н., Дегула Н.Р. Эффективность и безопасность лефлуномида при ревматоидном артрите в реальной клинической практике (результаты Российского наблюдательного многоцентрового исследования) // Современная ревматология. - 2014. - № 2. - С. 52-54.

4. Карпов А.М., Рвачева А.В., Шогенова М.Х., Жетишева Р.А., Масенко В.П., Наумов В.Г. Современные представления об иммуновоспалительных механизмах атеросклероза // Атеросклероз и дислипидемии. - 2014. - № 1. - С. 25-30.

5. Князева Л.А., Мещчерина Н.С., Горяйнов И.И., Князева Л.И., Степченко М.А., Безгин А.В., Гришина О.В., Понкратов В.И. Оценка состояния эндотелиальной функции и ригидности артериальной стенки у больных ревматоидным артритом // Курский научно-практический вестник «Человек и его здоровье». - 2013. - № 4. - С. 78-84.

6. Мазуров В.И., Жугрова Е.С. Лефлуномид в лечении ревматоидного артрита // Русский медицинский журнал. - 2013. - № 6. - С. 328-331.

7. Марков Х.М. Оксид азота и атеросклероз. Фармакотерапия атеросклероза и оксид азота // Кардиология. - 2011. - № 3. - С. 86-94.

8. Насонов Е.Л. Новые направления фармакотерапии ревматоидного артрита: блокада интерлейкина 6 и В-лимфоцитов // Клиническая фармакология и терапия. - 2010. - № 19 (1). - С. 70-78.

9. Насонов Е.Л. Прогресс ревматологии в начале XXI века // Современная ревматология. - 2014. № 3. - C. 4-8.

10. Насонов Е.Л., Мазуров В.И., Каратеев Д.Е., Лукина Г.В., Жиляев Е.В., Амирджанова В.Н., Муравьев Ю.В., Чичасова Н.В. Проект рекомендаций по лечению ревматоидного артрита Общероссийской общественной организации «Ассоциация ревматологов России» - 2014 (часть 1) // Научно-практическая ревматология. - 2014. - № 52 (5). C. 477-494.

11. Олюнин Ю.А. Лефлуномид при ревматоидном артрите: актуальные вопросы практического применения // Современная ревматология. - 2009. - № 3. - С. 72-79.

12. Олюнин Ю.А. Лефлуномид в клинической практике // Современная ревматология. - 2014. - № 1. C. 59-63.

13. Парфенов А.С. Экспресс-диагностика сердечно-сосудистых заболеваний // Мир измерений. - 2008. № 6. - С. 74-82.

14. Парфенов А.С. Ранняя диагностика сердечно-сосудистых заболеваний с использованием аппаратнопрограммного комплекса «Ангиоскан-01» // Поликлиника. - 2012. - № 2. - С. 1-5.

15. Ревматология: клинические рекомендации / под ред. Е.Л. Насонова. - М. : ГЭОТАР-Медиа, 2010. $752 \mathrm{c}$.

16. Чичасова Н.В., Насонов Е.Л. Лефлуномид в лечении ревматических заболеваний. - М. : МегаПро, 2010. $-92 \mathrm{c}$.

17. Kozera L., Andrews J., Morgan A.W. Cardiovascular risk and rheumatoid arthritis the next step: differrentiating true soluble biomarkers of cardiovascular risk from surrogate measures of inflammation // Rheumatology. - 2011. - Vol. 50, N 11. - P. 1944-1954.

18. Laurent S., Cockcroft J., Van Bortel L., Boutouyrie P., Giannattasio C., Hayoz D., Pannier B., Vlachopoulos C., Wilkinson I., Struijker-Boudier H.; European Network for Non-invasive Investigation of Large Arteries. Expert consensus document on arterial stiffness: methodological issues and clinical applications // Eur. Heart J. - 2006. - Vol. 27, N 21. P. 2588-2605.

19. Mitchell G.F., Hwang S.J., Vasan R.S., Larson M.G., Pencina M.J., Hamburg N.M., Vita J.A., Levy D., Benjamin E.J. Arterial stiffness and cardiovascular events: the Framingham Heart Study // Circulation. 2010. - Vol. 121, N 4. - P. 505-511.

20. Naranjo A., Sokka T., Descalzo M.A., Calvo-Alen J., Horslev-Petersen K., Luukkainen R.K., Combe B., Burmester G.R., Devlin J., Ferraccioli G., Morelli A., Hoekstra M., Majdan M., Sadkiewicz S., Belmonte M., Holmqvist A.-C., Choy E., Tunc R., Dimic A., Bergman M., Toloza S., Pincus T. for the QUEST-RA Group. Cardiovascular disease in patients with rheumatoid arthritis: results from the QUEST-RA study //Arthris. Res. Ther. - 2008. - Vol. 10, N 2. P. R30. 